\title{
ПРОЦЕСС ВЗАИМОДЕЙСТВИЯ СУБЪЕКТОВ НЕГОСУДАРСТВЕННОГО ПЕНСИОННОГО ОБЕСПЕЧЕНИЯ НА РЫНКЕ ФИНАНСОВЫХ УСЛУГ
}

\begin{abstract}
В статье исследован процесс взаимодействия субъектов негосударственного пенсионного обеспечения. Рассмотрены актуальные вопросы функционирования субъектов негосударственного пенсионного обеспечения. Предложено создание кластера субъектов негосударственного пенсионного обеспечения. Выделены основные факторы влияющие на выбор потенциальной кластеризации субъектов НПО: доход от инвестиций, взносы по собственному желанию, самостоятельность при выборе схемы оплаты, наличие конкретного срока взносов. В качестве альтернатив иерархической модели кластеризации субъектов НПО предложены: кластер 1: страховая компания, банк, НПФ и субъект предпринимательства; кластер 2: страховая компания, НПФ и субъект предпринимательства; кластер 3: страховая компания, банк и субъект предпринимательства; кластер 4: банк, НПФ и субъект предпринимательства. Результаты оценки глобального вектора приоритетов влияния факторов на выбор потенциального кластера субъектов НПО свидетельствуют о том, что предпочтение следует отдать кластеру 1 , в который входит страховая компания, банк, НПФ и субъект предпринимательства. Дальнейшее развитие кластера 1 в современных условиях приведёт к реализации ключевых принципов становления стратегических ориентиров в НПО, а именно: улучшение инвестиционного климата; накопления и привлечения долгосрочного капитала в инвестиционную сферу; возможность предоставления клиентам полного и широкого спектра услуг; единственная клиентская база; достаточная заинтересованность работодателей в финансировании пенсионных программ для работников. Взаимодействие субъектов НПО проложит путь к повышению уровня пенсионного обеспечения, легализации заработных плат и получению льгот налогообложения. НПФ является ядром кластера, в результате чего деятельность кластера будет направлена на расширение финансово-инвестиционных возможностей, увеличение престижности и социальной привлекательности.
\end{abstract}

Ключевые слова: негосударственное пенсионное обеспечение, страховая компания, банк, кластер, рынок финансовых услуг.

\footnotetext{
${ }^{1}$ Yevgenya Olehovna Malyshko (Евгения Олеговна Малышко) - аспирант кафедры управления финансовыми услугами Харьковского национального экономического университета, Украина, 61166, г. Харьков, пр. Ленина, 9a; e-mail: jekiaj@ukr.net
} 


\section{ВВЕДЕНИЕ}

Ориентированность государства на социальную защиту населения является главной задачей, которая проложит путь к внедрению новых пенсионных моделей долгосрочного накопления инвестиций. Негосударственное пенсионное обеспечение - это эффективный финансовый инструмент, который способствует решению глобальных вопросов в системе социального страхования.

Весомый вклад в исследовании взаимодействии субъектов негосударственного пенсионного обеспечения внесли Н.Н. Внукова ${ }^{2}$, О.А. Ягольницький ${ }^{3}$, О.А. Землячкова ${ }^{4}$, Ю.К. Костюк ${ }^{5}$, Ф.О. Журавко, Н.О. Небаба ${ }^{6}$ и др.

Исследования в области негосударственного пенсионного обеспечения, свидетельствует о необходимости в расширении направлений инвестирования пенсионных активов при наличии благоприятных условий на фондовом рынке и макроэкономической стабильности; расширить использование финансовых

2 К угрозам негосударственного пенсионного обеспечения можно отнести отсутствие гарантированной доходности, низкую ликвидность украинского фондового рынка, отсутствие достаточного объёма качественных активов, соответствующих нормативным требованиям, отсутствие доступа к ликвидным рынкам (инвестирование заграницу), недоверие, экономический кризис и нестабильность экономики. Внукова Н.Н. Организация негосударственного пенсионного обеспечения: SWOT - анализ и рекомендации для работников высшей школь / Н.М. Внукова // Пенсионная реформа в Украине: роль финансовых консультантов / Материалы II Всеукраинского форума. - Ирпень - М.: НУГНС Украины. - С. 46-50.

${ }^{3}$ В статье определено группы организаций, среди потенциальных участников финансового кластера, которые должны быть ядром. Выделены основные финансовые учреждения, которые целесообразно объединятся ты в финансовый кластер и установлена степень взаимодействия между ними. Ягольницкий А.А. Анализ взаимодействия участников финансового кластера / А.А. Ягольницкий // Вестник экономики транспорта и промышленности. - 2011. - № 34. - С. 427-430

${ }^{4}$ Выделены основные принципы во взаимодействии коммерческих банков со страховыми компаниями. Процессы интеграции, происходящие ныне в финансовой и экономической сферах, затрагивающих всех субъектов рынка, в том числе банки и страховые компании. Финансовый рынок становится все более конкурентным, что требует от его участников поиска новых форм и методов работы, способствующих получению конкурентных преимуществ. Землячова А.А. Взаимодействие коммерческих банков со страховыми компаниями на рынке финансовых услуг / О.А. Землячова // эконмика Kрыммa . - 2012. - № 2 (39). - C. 185-188.

5 С целью повышения конкурентоспособности отечественных финансовых учреждений необходимым является объединение усилий различных участников рынка финансовых услуг. Костюк Ю.К. Особенности объединения финансовых учреждений в финансовые кластеры [ Электронный ресурс $]$. - Режим доступа: http://archive.nbuv.gov.ua /portal/Soc_Gum/fkd/2010_2/R2/23.PDF.

${ }^{6}$ Рассмотрена структура пенсионной системы Украины и состав основных его участников. Исследованы границы участия негосударственных пенсионных фондов, страховых компаний и банков в негосударственном пенсионном обеспечении. Журавко Ф.А., Небаба Н.А. Особенности участия негосударственных пенсионных фондов, страховых компаний и банков в негосударственном пенсионном обеспечении / Ф.А. Журавко, Н.А. Небаба // Экономический форум . - 2012. - № 2 . - С. 373-377. 
инструментов, в которые НПФ сможет вкладывать свои активы; внедрить гибкие требования к дифференциации активов НПФ ${ }^{7}$.

\section{ИССЛЕДОВАНИЕ ПРОЦЕССА ВЗАИМОДЕЙСТВИЯ СУБЬЕКТОВ НЕГОСУДАРСТВЕННОГО ПЕНСИОННОГО ОБЕСПЕЧЕНИЯ НА РЫНКЕ ФИНАНСОВЫХ УСЛУГ}

Кластер является одним из новых приоритетных форм организации. Его сущность заключается во взаимодействии групп компаний с особыми деловыми и финансовыми целями, основанных на системе долгосрочных взаимоотношений. Создание финансового кластера субъектов негосударственного пенсионного обеспечения позволит получить более эффективное сотрудничество на рынке финансовых услуг, что в результате даст возможность расширение инвестиционной деятельности.

Основной целью создания кластера является повышение конкурентоспособности его участников путём внедрения универсального финансового института с разнообразным спектром услуг, что в результате обеспечит эффективное управление денежными средствами, уменьшение управленческих расходов и повышение норм доходности инвестиционных ресурсов.

\section{МЕТОДОЛОГИЯ ИССЛЕДОВАНИЯ}

Для анализа иерархий было предложено применить метод Т. Саати (МАИ) ${ }^{8}$, который позволит учесть различные точки зрения участников и прийти к согласованности в процессе обсуждения.

Метод анализа иерархий позволяет конструировать модель решения проблемы, который учитывает взаимозависимость факторов внешней среды, активных субъектов отношений среды и рассматриваемой организационной системы (актеров), мотивацию их деятельности (цели, что они стремятся реализовать) и возможные сценарии развития событий в прогнозном будущем. Анализ можно проводить по двум этапам. За первым шагом проводится формулирование приоритетов каждого участника, определение средних оценок и уровня их согласованности. За вторым - происходит оценка приоритетов в процессе проведения общей дискуссии и получения консенсусной оценки. МАИ (метода анализа иерархий) позволяет определить приоритеты участников, основываясь на

\footnotetext{
7 Оценены основные показатели деятельности негосударственных пенсионных фондов, по результатам доли объектов инвестирования в общей стоимости активов. Установлено с помощью интегрального показателя влияние факторов на уровень развития негосударственных пенсионных фондов. Рассмотрены сущность пенсионной системы и развитие негосударственных пенсионных фондов в Польше. Определены основные приоритеты дальнейшего развития. Малышко Е.О., Рышард Пукала Анализ развития негосударственных пенсионных фондов / Е.О. Малышко, Рышард Пукало // Научный журнал «Экономика развития». - М.: Изд.: ХНЭУ. - 2012. - № 4 ( 64). - С.29 -36.

8 МАИ (метода анализа иерархий) позволяет определить приоритеты участников, основываясь на их «нечетких» рассуждениях и анализе, то есть перейти от субъективнокачественной к объективно-количественной оценки. Саати Т. Принятие решений. Метод анализа иерархий / Т. Саати; [пер.с англ. Р.Г. Ваченадзе]. - М.: Радио и связь. - 2004. -278c.
} 
их «нечетких» рассуждениях и анализе, то есть перейти от субъективнокачественной к объективно-количественной оценке.

Шкала баллов по методике Т. Саати целыми нечётными числами от 1 до 9 включительно. Значение бальных оценок представлены в табл.1.

Таблица 1. Шкала оценки по методике Т. Саати

\begin{tabular}{|c|c|c|}
\hline $\begin{array}{l}\text { Уровень } \\
\text { значимости }\end{array}$ & Определения & Объяснения \\
\hline 1 & Одинаковая значимость & $\begin{array}{l}\text { Два объекты (действия) имеют } \\
\text { одинаковый вклад по достижению } \\
\text { цели }\end{array}$ \\
\hline 3 & $\begin{array}{l}\text { Незначительное } \\
\text { преобладание значимости } \\
\text { одного объекта (действия) } \\
\text { над другим }\end{array}$ & $\begin{array}{l}\text { Существуют мнения относительно } \\
\text { преобладания одного объекта над } \\
\text { другим, однако они недостаточно } \\
\text { убедительными }\end{array}$ \\
\hline 5 & $\begin{array}{l}\text { Существенная или сильная } \\
\text { значимость }\end{array}$ & $\begin{array}{l}\text { Существуют достоверные данные или } \\
\text { логические суждения относительно } \\
\text { преобладания одного объекта над } \\
\text { другим }\end{array}$ \\
\hline 7 & $\begin{array}{l}\text { Очевидна или очень сильная } \\
\text { значимость }\end{array}$ & $\begin{array}{l}\text { Существуют убедительные } \\
\text { свидетельства относительно } \\
\text { преобладания одного объекта над } \\
\text { другим }\end{array}$ \\
\hline 9 & Абсолютная значимость & $\begin{array}{l}\text { Существуют свидетельства } \\
\text { относительно преобладания одного } \\
\text { объекта над другим, которые в } \\
\text { значительной степени убедительными }\end{array}$ \\
\hline $2,4,6,8$ & $\begin{array}{l}\text { Промежуточные значения } \\
\text { между смежными уровнями } \\
\text { значимости }\end{array}$ & $\begin{array}{l}\text { Ситуация, когда необходимо } \\
\text { компромиссное решение }\end{array}$ \\
\hline
\end{tabular}

Матрица оценок заполняется с использованием правила:

$$
a_{i j}=\frac{1}{a_{i j}},
$$

где ајі - элемент матрицы і - й строки ј - го столбца.

Вектор направленности рассчитывается по формуле (2): 


$$
\overline{\left(x_{1}, x_{2}, \ldots, x_{n}\right)}=\left[\begin{array}{lll}
\sum_{j=1}^{n} a 1_{j} & \sum_{j=1}^{n} a n j \\
\sum_{t=1}^{n} \sum_{j=1}^{n} a j & \ldots . ., & \frac{\sum_{n=1}^{n} \sum_{j=1}^{n} a u j}{n}
\end{array}\right]
$$

где ајі - элемент матрицы і - й строки ј - го столбца.

В процессе исследования был проведён опрос экспертов - специалистов в сфере финансов. В экспертную группу вошли учёные (кандидаты и доктора наук), занимающиеся исследованиями в области рыночных услуг, управления персоналом, финансов, системного анализа, бухгалтерского учёта, магистры по финансам, занимающиеся исследованиями рынка финансовых услуг.

\section{ОСНОВНАЯ ЧАСТЬ}

Анализ иерархий представляет собой выбор условий потенциальной кластеризации субъектов негосударственного пенсионного обеспечения. С целью активизирования взаимовыгодной от сотрудничества страховой компании, банка, НПФ и субъекта предпринимательства автором предложены (см. рис.1.) кластеры и проанализированы приоритеты влияния на выбор потенциальной кластеризации субъектов НПО.

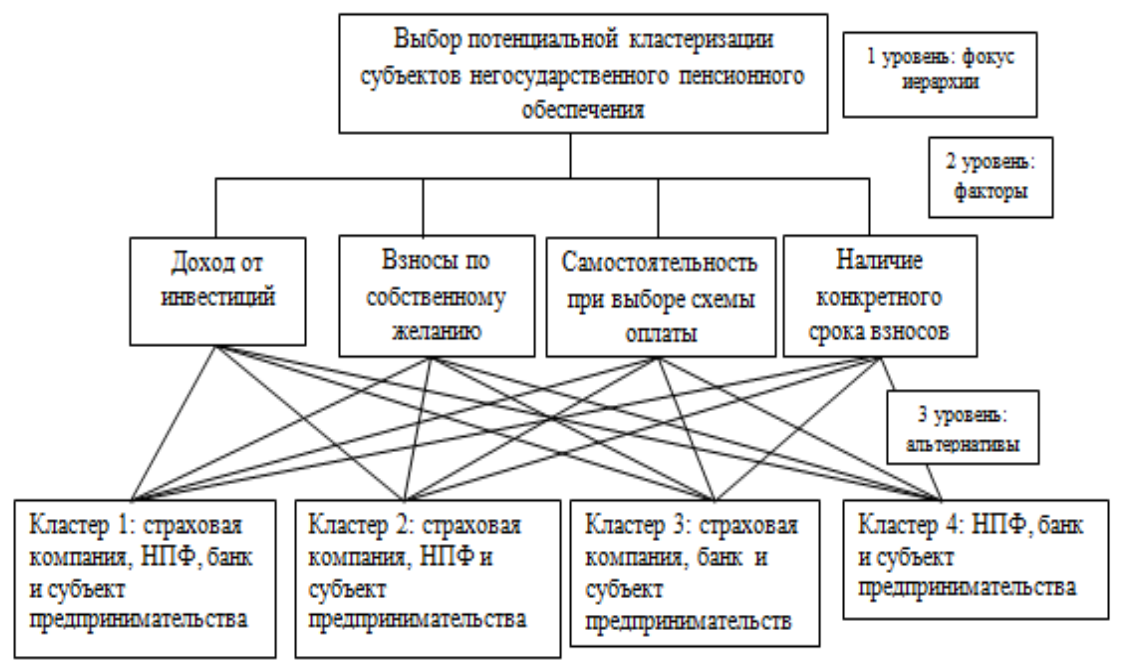

Рис. 1. Иерархическая модель кластеризации субъектов негосударственного пенсионного обеспечения 
На первом этапе определены приоритеты влияния на выбор потенциальной кластеризации субъектов НПО (див.табл. 2) и дали оценку каждому приоритету от 1 до 9 в зависимости от значимости фактора. В качестве факторов были выделены: доход от инвестиций, взносы по собственному желанию, самостоятельность при выборе схемы оплаты, наличие конкретного срока взносов.

С целью более чёткого определения выделенных факторов ,влияющих на выбор потенциального кластера НПО, охарактеризуем каждый из них: доход от инвестиций (предоставление участникам и вкладчикам защиты пенсионных взносов от инфляции с целью увеличения пенсионных накоплений); взносы по собственному желанию (предусматривает выбор субъектов НПО); самостоятельность при выборе схемы оплаты (возможность накопления пенсионных сбережений на принципах диверсификации); наличие конкретного срока взносов (способность инвестирования пенсионных средств на долгосрочную перспективу).

Таблица 2. Определение факторов влияния на выбор потенциальной кластеризации субъектов НПО

\begin{tabular}{|l|c|c|c|c|}
\hline Фактор & $\begin{array}{l}\text { Доход от } \\
\text { инвестиц } \\
\text { ий }\end{array}$ & $\begin{array}{l}\text { Взносы по } \\
\text { собственно } \\
\text { му } \\
\text { желанию }\end{array}$ & $\begin{array}{l}\text { Самостоятельност } \\
\text { ь при выборе } \\
\text { схемы оплаты }\end{array}$ & $\begin{array}{l}\text { Наличие } \\
\text { конкретного } \\
\text { срока взносов }\end{array}$ \\
\hline $\begin{array}{l}\text { Доход от } \\
\text { инвестиций }\end{array}$ & 1 & 6 & 5 & 9 \\
\hline $\begin{array}{l}\text { Взносы по } \\
\text { собственному } \\
\text { желанию }\end{array}$ & $1 / 6$ & 1 & 2 & 3 \\
\hline $\begin{array}{l}\text { Самостоятельнос } \\
\text { ть при выборе } \\
\text { схемы оплаты }\end{array}$ & $1 / 5$ & $1 / 2$ & 1 & 1 \\
\hline $\begin{array}{l}\text { Наличие } \\
\text { конкретного } \\
\text { срока взносов }\end{array}$ & $1 / 9$ & $1 / 4$ & $1 / 3$ & \\
\hline
\end{tabular}

В табл. 3 представлен расчёт главного вектора и вектора приоритетов потенциальной кластеризации субъектов НПО.

Таблица 3. Значение главного собственного вектора и вектора приоритетов

\begin{tabular}{|c|c|c|c|c|c|}
\hline Приоритет & $\begin{array}{c}\text { Главный } \\
\text { собственный } \\
\text { вектор }\end{array}$ & $\begin{array}{c}\text { Вектор } \\
\text { приоритетов }\end{array}$ & $\lambda$ & ИС & ОС \\
\hline Доход от инвестиций & 4,054 & 0,660 & 4,141 & 0,047 & 0,051 \\
\hline
\end{tabular}




\begin{tabular}{|c|c|c|}
\hline $\begin{array}{l}\text { Взносы по собственному } \\
\text { желанию }\end{array}$ & 1,075 & 0,173 \\
\hline $\begin{array}{l}\text { Самостоятельность при } \\
\text { выборе схемы оплаты }\end{array}$ & 0,740 & 0,117 \\
\hline $\begin{array}{l}\text { Наличие конкретного } \\
\text { срока взносов }\end{array}$ & 0,310 & 0,050 \\
\hline
\end{tabular}

Исследовано влияние каждого фактора на выделенные автором потенциальные кластеры НПЗ (см. табл. 4 - 7).

Таблица 4. Определение влияния фактора - доход от инвестиций на выбор кластера субъектов НПО

\begin{tabular}{|c|c|c|c|c|c|c|c|c|}
\hline $\begin{array}{c}\text { Фактор: } \\
\text { Доход от } \\
\text { инвестиц } \\
\text { ий }\end{array}$ & K1 & K2 & K3 & K4 & $\begin{array}{c}\text { Главный } \\
\text { собственны } \\
\text { й вектор }\end{array}$ & $\begin{array}{c}\text { Вектор } \\
\text { приорите } \\
\text { тов }\end{array}$ & $\lambda$ & IC \\
\hline K1 & 1 & 2 & 6 & 9 & 3,224 & 0,534 & \multirow[t]{4}{*}{4,231} & \multirow[t]{4}{*}{0,077} \\
\hline K2 & $1 / 2$ & 1 & 4 & 5 & 1,778 & 0,301 & & \\
\hline K4 & $1 / 6$ & $1 / 4$ & 1 & 5 & 0,676 & 0,120 & & \\
\hline K4 & $1 / 9$ & $1 / 5$ & $1 / 5$ & 1 & 0,258 & 0,045 & & \\
\hline
\end{tabular}

Таблица 5. Определение влияния фактора - взносы по собственному желанию на выбор кластера субъектов НПО

\begin{tabular}{|c|c|c|c|c|c|c|c|c|}
\hline $\begin{array}{c}\text { Фактор: } \\
\text { Взносы } \\
\text { по } \\
\text { собственн } \\
\text { ому } \\
\end{array}$ & K1 & K2 & К3 & K4 & $\begin{array}{c}\text { Главный } \\
\text { собственн } \\
\text { ый вектор }\end{array}$ & $\begin{array}{c}\text { Вектор } \\
\text { приоритето } \\
\text { в }\end{array}$ & $\lambda$ & IC \\
\hline K1 & 1 & 5 & 4 & 6 & 3,310 & 0,592 & \multirow[t]{4}{*}{4,153} & \multirow[t]{4}{*}{0,051} \\
\hline K2 & $1 / 5$ & 1 & $1 / 5$ & $1 / 2$ & 0,376 & 0,067 & & \\
\hline K4 & $1 / 4$ & 5 & 1 & 3 & 1,392 & 0,243 & & \\
\hline K4 & $1 / 6$ & 2 & $1 / 3$ & 1 & 0,577 & 0,098 & & \\
\hline
\end{tabular}


Таблица 6. Определение влияния фактора - самостоятельности при выборе схемы оплаты на выбор кластера субъектов НПО

\begin{tabular}{|c|c|c|c|c|c|c|c|c|}
\hline $\begin{array}{c}\text { Фактор: } \\
\text { Самостоя } \\
\text { тельность } \\
\text { при }\end{array}$ & K1 & $\mathrm{K} 2$ & K3 & K4 & $\begin{array}{c}\text { Главный } \\
\text { собственн } \\
\text { ый вектор }\end{array}$ & $\begin{array}{c}\text { Вектор } \\
\text { приоритето } \\
\text { в }\end{array}$ & $\lambda$ & IC \\
\hline K1 & 1 & 7 & 3 & 2 & 2,546 & 0,492 & \multirow[t]{4}{*}{4,037} & \multirow[t]{4}{*}{0,012} \\
\hline $\mathrm{K} 2$ & $1 / 7$ & 1 & $1 / 2$ & $1 / 4$ & 0,366 & 0,07 & & \\
\hline K4 & $1 / 3$ & 2 & 1 & $1 / 3$ & 0,686 & 0,133 & & \\
\hline K4 & $1 / 2$ & 4 & 3 & 1 & 1,565 & 0,304 & & \\
\hline
\end{tabular}

Таблица 7. Определение влияния фактора - наличия конкретного срока взносов на выбор кластера субъектов НПО

\begin{tabular}{|c|c|c|c|c|c|c|c|c|}
\hline $\begin{array}{l}\text { Фактор: } \\
\text { Наличие } \\
\text { конкретн } \\
\text { ого срока }\end{array}$ & K1 & K2 & K3 & K4 & $\begin{array}{c}\text { Главный } \\
\text { собственн } \\
\text { ый вектор }\end{array}$ & $\begin{array}{c}\text { Вектор } \\
\text { приоритето } \\
\text { в }\end{array}$ & $\lambda$ & IC \\
\hline 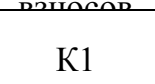 & 1 & $1 / 2$ & 3 & 4 & 2,121 & 0,253 & \multirow[t]{4}{*}{4,369} & \multirow[t]{4}{*}{0,123} \\
\hline K2 & 2 & 1 & 9 & 7 & 3,350 & 0,577 & & \\
\hline K4 & $1 / 3$ & $1 / 9$ & 1 & 5 & 0,656 & 0,120 & & \\
\hline K4 & $1 / 4$ & $1 / 7$ & $1 / 5$ & 1 & 0,582 & 0,051 & & \\
\hline
\end{tabular}

Определено размерность выделенных факторов при $\mathrm{n}=4$ (см. табл. 8). 
Таблица 8. Расчёт значения выделенных факторов

\begin{tabular}{|c|c|c|c|c|}
\hline Значение & $\begin{array}{c}\text { Доход от } \\
\text { инвестиций }\end{array}$ & $\begin{array}{c}\text { Взносы по } \\
\text { собственному } \\
\text { желанию }\end{array}$ & $\begin{array}{c}\text { Самостоятель } \\
\text { ность при } \\
\text { выборе схемы } \\
\text { оплаты }\end{array}$ & $\begin{array}{c}\text { Наличие } \\
\text { конкретного } \\
\text { срока взносов }\end{array}$ \\
\hline ОС & 0,084 & 0,077 & 0,02 & 0,013 \\
\hline
\end{tabular}

На основании данных табл. 4 - 7 определена вероятность реализации соответствующих альтернатив глобального вектора приоритетов влияния факторов на выбор потенциального кластера субъектов негосударственного пенсионного обеспечения, что представлено в табл. 9.

Потенциальная кластеризация субъектов НПО создаст новые перспективы во взаимодействии НПФ, страховых компаний, банков и субъектов предпринимательства, что позволит повышению финансовых возможностей и увеличит уровень заинтересованности потенциальных участников кластера в привлечении инвестиций.

Таблица 9. Результаты оценки глобального вектора приоритетов факторов на выбор потенциального кластера субъектов НПО

\begin{tabular}{|c|c|c|c|c|}
\hline $\begin{array}{c}\text { Альтерн } \\
\text { атива }\end{array}$ & $\begin{array}{c}\text { Кластер 1: } \\
\text { страховая } \\
\text { компания, НПФ, } \\
\text { банк, субъект } \\
\text { предпринима- } \\
\text { тельства }\end{array}$ & $\begin{array}{c}\text { Кластер 2: } \\
\text { страховая } \\
\text { компания, } \\
\text { НПФ, субъект } \\
\text { предпринима- } \\
\text { тельства } \\
\text { компания, банк, } \\
\text { субъект } \\
\text { предпринима- } \\
\text { тельства }\end{array}$ & $\begin{array}{c}\text { Кластер 3: } \\
\text { страховьект } \\
\text { предприни } \\
\text { ма-тельства }\end{array}$ \\
\hline $\begin{array}{c}\text { Оценка } \\
\text { глобальн } \\
\text { ого } \\
\text { вектора }\end{array}$ & 0,525 & 0,247 & 0,141 & 0,087 \\
\hline
\end{tabular}

В табл. 9 представлены результаты оценки глобального вектора приоритетов влияния факторов на выбор потенциального кластера субъектов НПО. Полученные данные свидетельствуют, что предпочтение следует отдать в первую очередь кластеру 1 (страховая компания, НПФ, банк и субъект предпринимательства) значение которого более $50 \%$, далее кластер 2 , который включает в себя страховую компанию, НПФ и субъект предпринимательства с 25\%. Кластер 3: страховая компания, банк и субъект предпринимательства - был получен результат оценки глобального вектора приоритетов влияния факторов на выбор потенциального кластера субъектов НПО - 14\%. Кластер 4: НПФ, банк и субъект 
предпринимательства - оценка которого составила менее $10 \%$ от воздействия выделенных факторов.

\section{ВЫВОД}

Следовательно, развитие кластера, в который входит страховая компания, НПФ, банк и субъект предпринимательства, в современных условиях является организационной основой для реализации ключевых принципов становления стратегических ориентиров в НПО. Следует отметить, что НПФ является ядром кластера, в результате чего, деятельность кластера будет направлена на расширение финансово-инвестиционных возможностей, увеличение престижности и социальной привлекательности. Взаимодействие субъектов НПО откроет путь к повышению уровня пенсионного обеспечения, легализации заработных плат и получение льгот налогообложения.

Сотрудничество финансовых учреждений определяется возможностью получения положительного эффекта для всех, а именно: улучшения инвестиционного климата; накопления и привлечения долгосрочного капитала в инвестиционную сферу; возможности предоставления клиентам полного и широкого спектра услуг; единственной клиентской базы; достаточной заинтересованности работодателей в финансировании пенсионных программ для работников.

\section{ЛИТЕРАТУРА}

[1] Внукова Н.Н. Организация негосударственного пенсионного обеспечения: SWOT - анализ и рекомендации для работников высшей школы / Н.M. Внукова // Пенсионная реформа в Украине: роль финансовых консультантов / Материалы II Всеукраинского форума. - Ирпень - М.: НУГНС Украины.

[2] Ягольницкий А.А. Анализ взаимодействия участников финансового кластера / А.А. Ягольницкий // Вестник экономики транспорта и промышленности, Украина 2011/34 .

[3] Землячова А.А. Взаимодействие коммерческих банков со страховыми компаниями на рынке финансовых услуг / О.А. Землячова // Экономика Крыма, Украина 2012/ 2 (39).

[4] Костюк Ю.К. Особенности объединения финансовых учреждений 6 финансовые кластеры [Электронный ресурс]. - Режим доступа: http://archive.nbuv.gov.ua /portal/Soc_Gum/fkd/2010_2/R2/23.PDF .

[5] Журавко Ф.А., Небаба Н.А. Особенности участия негосударственных пенсионных фондов, страховых компаний и банков в негосударственном пенсионном обеспечении / Ф.А. Журавко, Н.А. Небаба // Экономический форум, Украина 2012/ 2.

[6] Малышко Е.О., Рышард Пукала Анализ развития негосударственных пенсионных фондов / Е.О. Малышко, Рышард Пукала // Научный журнал «Экономика развития». - М.: Изд.: ХНЭУ 2012/ 4 ( 64).

[7] Саати Т. Принятие решений. Метод анализа иерархий / Т. Саати; [пер.с англ. Р.Г. Ваченадзе]. - Москва: Радио и связь 2004. 


\section{THE PROCESS OF INTERACTION OF SUBJECTS OF PRIVATE PENSION PROVISION IN THE FINANCIAL SERVICES}

The article studied the interaction of subjects of private pension provision. Discussed topical issues of functioning of the subjects of private pension provision. Proposed the creation of a cluster of subjects of private pension provision. Main factors influencing the choice of the potential clustering of subjects NGOs investment income, contributions by choice, autonomy in choosing payment scheme, the presence of a specific period of contributions. As alternatives to the hierarchical clustering model proposed NGO entities: Cluster 1: insurance companies, banks, pension funds and the business entity; cluster 2: insurance company, pension funds and the business entity; cluster 3: insurance company, a bank and a business entity; cluster 4: bank, NPF and the subject of entrepreneurship. The results of evaluation of the global vector of priorities of factors influence the choice of a potential cluster of subjects NGOs indicate that preference should be given to the cluster 1 , which includes insurance companies, banks, pension funds and the subject of entrepreneurship. Further development of cluster 1 in the present conditions will lead to the implementation of the key principles of formation of strategic guidelines to NGOs, namely: improving the investment climate; development and attracting long-term capital in the investment sphere; the ability to provide customers with a complete and wide range of services; the only client base; a sufficient interest to employers in the financing of pension schemes for employees. Interaction of subjects of NGOs put the path to raising the level of pension support, legalization of wages and benefits tax. NPF is the core of the cluster, as a result, the cluster's activities will be directed at expansion of financial and investment opportunities, increase the prestige and social attractiveness.

Keywords: non-state pension insurance company, a bank, a cluster market for financial services.

\section{PROCESY WSPÓŁPRACY PODMIOTÓW NIEPAŃSTWOWEGO ZABEZPIECZENIA EMERYTALNEGO NA RYNKU USEUG FINANSOWYCH}

W artykule dokonano analizy procesu wzajemnych relacji pomiędzy podmiotami funkcjonującymi w obszarze niepaństwowego zabezpieczenia emerytalnego (NZE). Rozpatrzono aktualne problemy funkcjonowania podmiotów niepaństwowego zabezpieczenia emerytalnego. Zaproponowano powołanie klastra podmiotów niepaństwowego zabezpieczenia emerytalnego. Wydzielono główne czynniki wpływające na wybór potencjalnych uczestników klastra NZE: dochód z inwestycji, dobrowolne wpłaty własne, samodzielność w wyborze schematu płatności, konkurencyjność okresu płatności. Jako alternatywy w hierarchicznym modelu klastra podmiotów NZE zaproponowano: klaster 1: zakład ubezpieczeń, bank, NZE i podmiot gospodarczy; klaster 2: zakład ubezpieczeń, NZE i podmiot gospodarczy; klaster 3: zakład ubezpieczeń, bank i podmiot gospodarczy; klaster 4: bank, NZE i podmiot gospodarczy. Wyniki oceny globalnego wektora priorytetów wpływu na wybór potencjalnego klastra podmiotów NZE świadczą o tym, że preferencje ukierunkowane są na klaster 1, w skład którego wchodzi zakład ubezpieczeń, bank, NZE, i podmiot gospodarczy. Dalszy rozwój klastra we współczesnych warunkach doprowadzi do realizacji kluczowych zasad budowania strategicznych kierunków w obszarze niepaństwowego zabezpieczenia emerytalnego, a zwłaszcza: polepszenie klimatu inwestycyjnego, pozyskania i gromadzenia długoterminowego kapitału inwestycyjnego, możliwość zaoferowania klientom pełnego i szerokiego spektrum usług, jedyną bazę klientów, wystarczające zainteresowanie ze strony pracodawców w finansowaniu programów emerytalnych dla swoich pracowników. Współpraca pomiotów NZE przyczyni się do podniesienia poziomu zabezpieczenia emerytalnego, legalizacji wynagrodzenia i uzyskania ulg podatkowych. NZE występuje jako jądro klastra, co 
spowoduje, że w konsekwencji działalność klastra będzie ukierunkowana na rozszerzenie możliwości finansowo-inwestycyjnych oraz podniesienie prestiżu i atrakcyjności socjalnej.

Słowa kluczowe: niepaństwowe zabezpieczenie emerytalne, zakład ubezpieczeń, bank, klaster, rynek usług finansowych.

DOI:10.7862/rz.2013.hss.18

Tekst złożono w redakcji: czerwiec 2013

Przyjęto do druku: wrzesień 2013 